\title{
Article \\ Closed Endotracheal Suctioning Impact on Ventilator-Related Parameters in Obstructive and Restrictive Respiratory Systems: A Bench Study
}

\author{
Fang Jung ${ }^{1,2,3} \oplus$, Shang-Shing P. Chou ${ }^{3}$, Shih-Hsing Yang ${ }^{1}$, Jau-Chen Lin ${ }^{1}$ and Guey-Mei Jow ${ }^{4, *}$ \\ 1 Department of Respiratory Therapy, Fu Jen Catholic University, New Taipei City 24205, Taiwan; \\ 078720@mail.fju.edu.tw (F.J.); 075147@mail.fju.edu.tw (S.-H.Y.); 080659@mail.fju.edu.tw (J.-C.L.) \\ 2 Graduate Institute of Biomedical and Pharmaceutical Science, Fu Jen Catholic University, \\ New Taipei City 24205, Taiwan \\ 3 Department of Chemistry, Fu Jen Catholic University, New Taipei City 24205, Taiwan; \\ 002181@mail.fju.edu.tw \\ 4 School of Medicine, Fu Jen Catholic University, New Taipei City 24205, Taiwan \\ * Correspondence: 039666@mail.fju.edu.tw; Tel.: +886-22-905-3424
}

Citation: Jung, F.; Chou, S.-S.P.; Yang

S.-H.; Lin, J.-C.; Jow, G.-M. Closed

Endotracheal Suctioning Impact on

Ventilator-Related Parameters in

Obstructive and Restrictive

Respiratory Systems: A Bench Study.

Appl. Sci. 2021, 11, 5266. https://

doi.org/10.3390/app11115266

Academic Editor: José Machado

Received: 29 April 2021

Accepted: 4 June 2021

Published: 6 June 2021

Publisher's Note: MDPI stays neutral with regard to jurisdictional claims in published maps and institutional affiliations.

Copyright: (c) 2021 by the authors Licensee MDPI, Basel, Switzerland. This article is an open access article distributed under the terms and conditions of the Creative Commons Attribution (CC BY) license (https:// creativecommons.org/licenses/by/ $4.0 /)$.
Featured Application: The presented paper evaluates disparities in ventilator-related parameters between a patient's pulmonary mechanic characteristics (airway resistance, lung compliance) and ventilation characteristics (pressure-controlled, volume-controlled) with a closed suctioning system. These results can provide safe and effective mechanical ventilation during the closed suctioning system in clinical care.

Abstract: A closed suctioning system (CSS) in patients with coronavirus disease 2019 (COVID-19) prevents spraying respiratory secretions into the environment during suction. However, it is not clear whether ventilation is maintained during the suction procedure, especially in patients with compromised pulmonary mechanics. This paper determines the effects of endotracheal tube (ETT) size, suction catheter size, and two lung mechanics (resistance and compliance) on ventilator-related parameters measured during suction. Suction was performed on an adult training lung, ventilated with either volume-controlled (VC-CMV) or pressure-controlled mandatory ventilation (PC-CMV), using ETT sizes of 6.5-8.0 mm paired with suction catheter sizes of 8-14 French (Fr). Peak inspiratory pressure (PIP) increased by $50 \%$ when the ETT's ventilation area was less than $25 \mathrm{~mm}^{2}$ in size, especially in patients with high airway resistance ventilated with VC-CMV. Positive end-expiratory pressure (PEEP) levels significantly decreased when using 14 Fr SC during VC-CMV and fewer effects during PC-CMV. Change of expiratory minute volume increased with higher outer diameter of suction catheters and decreased with severe lung compliance during PC-CMV. The change in ventilator-related parameters were intently monitored in the patient whose pulmonary mechanic was compromised through the CSS endotracheal tube suctioning procedures in clinical airway management.

Keywords: COVID-19; closed suctioning system; ventilator-related parameters; pulmonary mechanic; endotracheal tube suctioning; mechanical ventilation

\section{Introduction}

Closed suctioning was originally introduced for hygiene reasons and as a method of avoiding desaturation and reduction in lung volume during suctioning. In a closed suctioning system (CSS), the catheter is a part of the ventilator circuit and there is no need to disconnect the ventilator. Continuing connection to the ventilator helps prevent loss of both positive end-expiratory pressure (PEEP) and lung volume [1,2]. Thus, it may enable volume recruitment in the lung and avert a drop in oxygenation. CSS can thus reduce the risks of hypoxemia, atelectasis, and hemodynamic fluctuations [3]. 
During open endotracheal suctioning and disconnection of a ventilator, patients may be exposed to a sudden unintended withdrawal of PEEP, which may induce repeated lung derecruitment and hypoxia [4-6]. However, CSS can prevent alveolar derecruitment and maintain appropriate oxygenation through a steady functional residual capacity (FRC) $[3,4]$. Regional lung derecruitment after endotracheal suction has been measured by electrical impedance tomography. The results demonstrated that FRC decreased by $58 \pm 24 \%$ of baseline at disconnection and $22 \pm 10 \%$ further during open suctioning [7].

This study investigates an important question: whether ventilator-related parameters are maintained during a closed suctioning procedure. These procedures induce an increase in airway resistance $\left(R_{a w}\right)$, resulting from the insertion of a suction catheter (SC) into an endotracheal tube (ETT) with a narrower area. During mechanical ventilation, the peak inspiratory pressure (PIP) is higher to overcome the increased resistance. PIP is a predictor for pulmonary barotrauma in the indications for mechanical ventilation [8,9]. Barotrauma is a well-recognized complication of mechanical ventilation and frequently occurs in patients with a wide range of underlying pulmonary conditions [10].

The primary disease in the decline of pulmonary mechanics is divided into obstructive and restrictive respiratory diseases. Mechanical ventilation support is often needed when pulmonary mechanics cannot function properly. Obstructive diseases can cause unstable airways that are prone to collapse, leading to difficulty in exhaling full tidal volume before the next breath, known as dynamic hyperinflation, which occurs in conditions such as asthma and chronic obstructive pulmonary disease (COPD) $[9,11]$. Mechanical ventilation can alleviate this problem by reducing minute volume and extending expiratory time. In some cases, it is necessary to increase the external PEEP for ventilator synchronization [12-14]. However, little research has been carried out on the use of CSS in obstructive disease patients for endotracheal suctioning.

Furthermore, restrictive diseases impair compliance in pulmonary mechanics. Acute respiratory distress syndrome (ARDS) features severe inflammation caused by impairment of lung compliance [15,16]. Mechanical ventilation is an essential life support for these patients; it maintains the openness of the lungs, minimizing lung injury caused by repetitive alveolar collapse and overdistention $[13,17,18]$. Clinical management aims to significantly reduce end-expiratory lung volume via CSS to avoid repetitive alveolar collapse and oxygen desaturation during suctioning [4]. However, guidelines for clinical endotracheal suctioning practices are needed in regard to how to ventilate the critically ill, with or without ARDS [13,19,20].

Therefore, clinical trials have focused on those patients who can benefit clinically from CSS. However, airway disease or lung tissue disease will affect real-time ventilator-related parameters during the CSS suction procedure, at a scale that is yet to be defined. This study aimed to determine the effects of endotracheal tube size, suction catheter size, different modes (VC-CMV and PC-CMV), and pulmonary mechanics (obstructive and restrictive) on ventilator-related parameters. Suction was performed on a simulated lung model with operating ventilation mode.

\section{Materials and Methods}

The study examined the effects of progressive decline in pulmonary mechanics on ventilator-related parameters during the process of closed suction. Such patients often experience a life-threatening moment during the closed suctioning process used with mechanical ventilation in clinical practice. For the sake of ethics and patient safety, the experiment was carried out using an adult training lung (TTL) model in a university laboratory, without any human subjects involved in the procedure. It was not necessary to obtain ethical approval from the Institutional Review Board or Ethics Committee.

\subsection{Preparing the Lung Model and Closed Suction System}

The study adopted a TTL (model 5600i, Michigan Instruments Inc., Grand Rapids, MI, USA) fixed to an inside diameter (ID) $20 \mathrm{~mm}$ artificial plastic trachea, which was intubated 
with endotracheal tubes (Mallinckrodt Taper Guard Oral/Nasal Tracheal Tube, Cuffed, Murphy Eye, Covidien). TTL's mechanical ventilation was connected to a Hamilton G5 ventilator (Hamilton Medical, Bonaduz, Switzerland). The study simulated the restrictive respiratory system in the TTL, which had adjusted lung compliance $\left(\mathrm{C}_{\mathrm{rs}}\right)$ on both sides $\left(0.08,0.05,0.04,0.03,0.02,0.01 \mathrm{~L} \cdot \mathrm{cm} \mathrm{H}_{2} \mathrm{O}^{-1}\right)$. The increased airway resistance $\left(\mathrm{R}_{\mathrm{aw}}\right)$ $\left(5,10,20,30,40 \mathrm{~cm} \mathrm{H}_{2} \mathrm{O} \cdot \mathrm{L}^{-1} \cdot \mathrm{s}\right)$ simulated the obstructive respiratory system with a restrictor before the artificial airway. The lung compliance was set to $0.05 \mathrm{~L} \cdot \mathrm{cm} \mathrm{H}_{2} \mathrm{O}^{-1}$ in a simulated obstructive model, and the airway restrictor was set to $5 \mathrm{H}_{2} \mathrm{O} \cdot \mathrm{L}^{-1} \cdot \mathrm{s}$ in a simulated restrictive model.

For mimics in the clinical patient intubations, a 6.5 to $8.0 \mathrm{~mm}$ endotracheal tube (ETT), paired with a CSS catheter (Unimax Medical Systems, Inc., New Taipei City, Taiwan) of $8 \mathrm{Fr}$ to $14 \mathrm{Fr}$, was employed during closed suctioning. Thus, the experiment employed four ETTs of various IDs, paired with four CSS catheters of various outer diameters (ODs), including a $6.5 \mathrm{~mm}$ ETT paired with $8 \mathrm{Fr}, 10 \mathrm{Fr} \mathrm{SC}$; a $7.0 \mathrm{~mm}$ ETT paired with $10 \mathrm{Fr}$, $12 \mathrm{Fr} \mathrm{SC}$; a $7.5 \mathrm{~mm}$ ETT paired with $10 \mathrm{Fr}, 12 \mathrm{Fr} \mathrm{SC}$, and an $8.0 \mathrm{~mm}$ ETT paired with $12 \mathrm{Fr}$, 14 Fr SC. The percentages of SC (OD)/ETT (ID) ranged from $41 \%$ to $58 \%$. The Hamilton-G5 ventilated at a frequency of 15 breaths/minute, with a PEEP of $10 \mathrm{~cm} \mathrm{H}_{2} \mathrm{O}$ [7]. In VC-CMV mode, frequency was set at a tidal volume of $0.6 \mathrm{~L}$ with $60 \mathrm{~L} / \mathrm{min}$ of constant flow and a pause time of $0.5 \mathrm{~s}$. Inspiratory pressure was set at $20 \mathrm{~cm} \mathrm{H}_{2} \mathrm{O}$ with a time of $1.0 \mathrm{~s}$ for PC-CMV, see Figure 1.
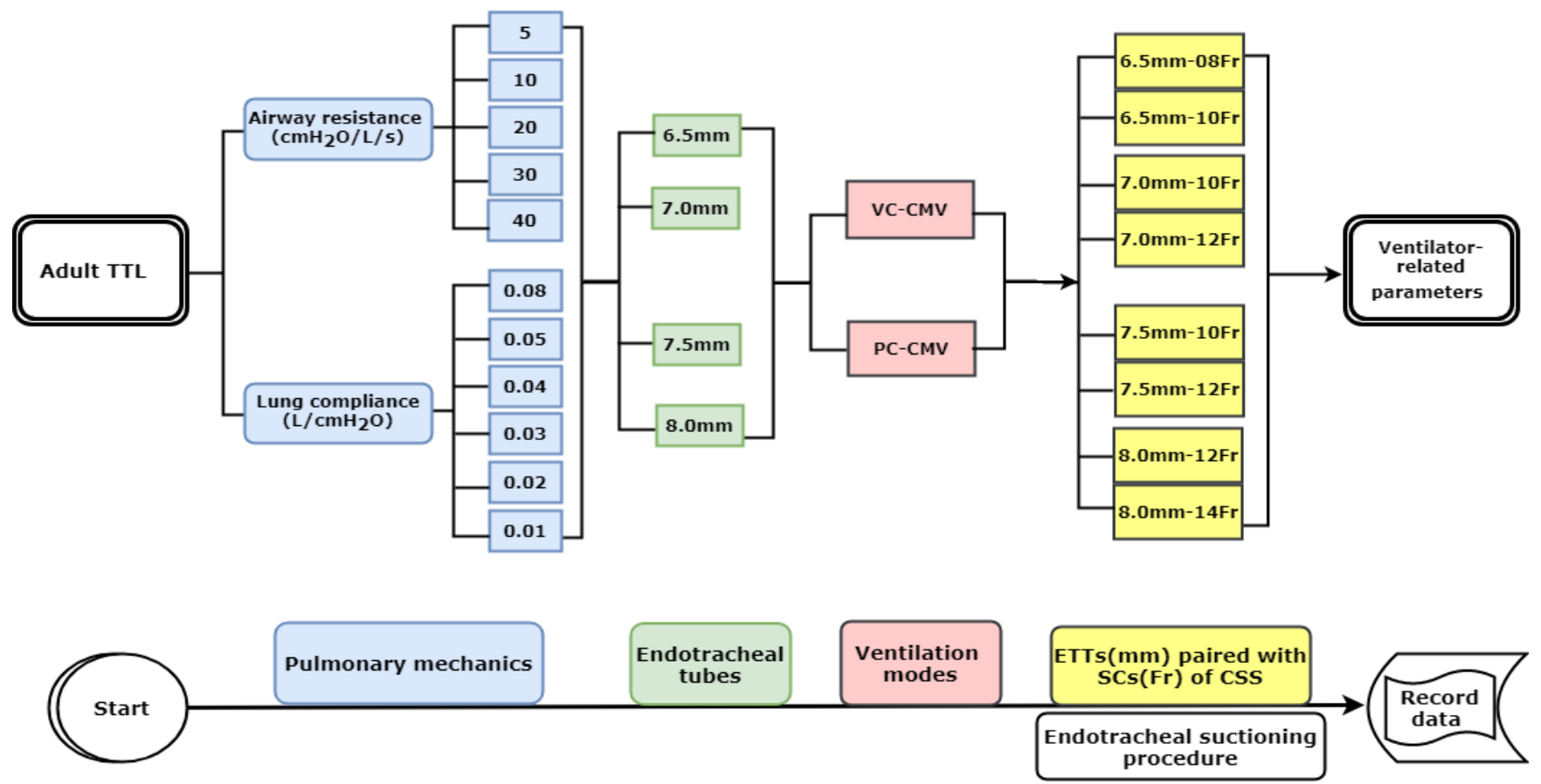

Figure 1. Experimental design and process. TTL: adult training lung; VC-CMV: volume control continuous mandatory ventilation; PC-CMV: pressure control continuous mandatory ventilation.

\subsection{Experimental Protocol}

Before the experiment, the flow sensor of the ventilator was calibrated and tested. The endotracheal tube cuff pressure is inflated at $50 \mathrm{~cm} \mathrm{H}_{2} \mathrm{O}$ to avoid the leak during ventilation. The CSS was a tight-fitting three-way device connecting the ventilator to the ETT and a suctioning apparatus (Pacific Hospital Supply Co., Ltd., Taipei, Taiwan) connection to a pressure gauge. The suction pressure applied to a vacuum level of $-150 \pm 10 \mathrm{mmHg}$.

The ventilator circuits were set up as standard adult double circuits without a humidifier to prevent any condensation effect. These circuits' compression ratio values stood at $2.1 \mathrm{~mL} / \mathrm{cm} \mathrm{H}_{2} \mathrm{O}$ at $0.05 \mathrm{~L} \cdot \mathrm{cm} \mathrm{H}_{2} \mathrm{O}^{-1}$ of lung compliance. The CSS suctioning system had a 
manually operated suction flow switch and a plastic sheath around it. During the suction process, a suction catheter was inserted at a spot $2 \mathrm{~cm}$ below the endotracheal tube tip [21] before being moved back to the plastic sheath.

The implementation of a continuous suction procedure was as follows. First, a suction catheter was inserted into the endotracheal tube without the application of suction; next, the catheter was moved to the plastic sheath with suctioning. Each complete suction process was performed in $15 \mathrm{~s}$ and repeated four times. Data on suctioning procedures were collected: the baseline ventilation status was recorded with the suction catheter standing by in the plastic sheath without any suction flow. Ventilator-related parameters were recorded for each ventilation episode by the Hamilton Medical ventilator data logger (version 3.27.1), including minute volume, airway pressure, $\mathrm{R}_{\mathrm{aw}}$, flow rate, time constant, and respiratory rate. Each time suctioning was completed, verification was sought that the ventilator had returned to baseline $\pm 10 \%$ within one minute.

\subsection{Statistical Analysis}

Data were input into software IBM SPSS Statistics 24 (IBM Corp., Armonk, NY, USA), including descriptive (mean, frequency) and analytical (independent $t$-test, ANOVA) statistics. Linear trend analysis was carried out to test the average value trends at each ordinal factor level. Multiple regression analysis estimates were made of the quantitative effects affecting airway pressure and minute volume. The significance level of the test was set at $<0.05$.

\section{Results}

\subsection{Effect of Closed Suction on Respiratory Resistance in Both Respiratory Systems}

The TTL was set for mechanical ventilation simulating restrictive disease with a gradual decline of $C_{r s}$ in pulmonary mechanics or obstructive disease with an increase of $\mathrm{R}_{\mathrm{aw}}$ in pulmonary mechanics. During endotracheal suctioning, insertion of the suction catheter into the endotracheal tube significantly increases respiratory resistance. The change of respiratory resistance was verified by the inspiratory resistance $\left(R_{I N S P}\right)$ and expiratory resistance $\left(R_{E X P}\right)$ levels. Results showed high levels of $R_{I N S P}$ and $R_{E X P}$ when CSS was applied in both ventilation modes (VC-CMV and PC-CMV), and a progressive decline in pulmonary mechanics (Table 1 ). The experiment showed that $\mathrm{R}_{\mathrm{INSP}}$ and $\mathrm{R}_{\mathrm{EXP}}$ levels' rise was higher in the obstructive respiratory system (Table 1a) than in the restrictive respiratory system (Table $1 b$ ). The increase in $R_{I N S P}$ was higher than the increase in $R_{E X P}$.

Furthermore, the study examined how closed suction induced a rise in the change of respiratory resistance and its effects on ventilator-related parameters in different ID endotracheal tubes paired with OD suction catheters, during the processes of PC-CMV and VC-CMV, for dissimilar pulmonary mechanics.

\subsection{Varied Effects of ETT and SC on PIP in Both Respiratory Systems}

Although VC-CMV enables the patient to receive a specific minute volume of ventilation, PIP varies in line with the change in the pulmonary mechanic of respiratory systems. The study examined the PIP effects on VC-CMV of endotracheal tubes paired with suction catheters in the closed suctioning system on two different pulmonary mechanics. Figure 2 shows an increase in PIP levels with a progressive decline in pulmonary mechanics during VC-CMV, with or without closed suctioning. The results exhibit significantly raised PIP levels along with a decline in pulmonary mechanics and small IDs of the endotracheal tubes. 


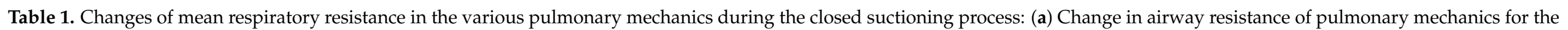

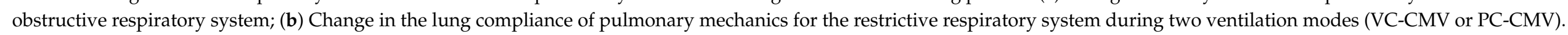

\begin{tabular}{|c|c|c|c|c|c|c|c|c|c|c|c|}
\hline \multicolumn{12}{|c|}{ (a) Obstructive Respiratory System } \\
\hline \multirow{3}{*}{ Variable } & \multirow{3}{*}{$\begin{array}{c}\mathrm{R}_{\mathrm{aw}} \\
\left(\mathrm{cm} \mathrm{H} \mathrm{H}_{2} \mathrm{O} \cdot \mathrm{L}^{-1} \cdot \mathrm{s}\right)\end{array}$} & \multicolumn{5}{|c|}{ VC-CMV } & \multicolumn{5}{|c|}{ PC-CMV } \\
\hline & & \multirow{2}{*}{ Mean } & \multirow{2}{*}{ SD } & \multirow{2}{*}{$p$-Value } & \multirow{2}{*}{ Post Hoc Test } & Linear Trend Analysis & \multirow{2}{*}{ Mean } & \multirow{2}{*}{ SD } & \multirow{2}{*}{$p$-Value } & \multirow{2}{*}{ Post Hoc Test } & Linear Trend Analysis \\
\hline & & & & & & $p$-Value & & & & & $p$-Value \\
\hline $\begin{array}{c}\mathrm{R}_{\mathrm{INSP}} \\
\left(\mathrm{cm} \mathrm{H} \mathrm{H}_{2} \mathrm{O} \cdot \mathrm{L}^{-1} \cdot \mathrm{s}\right)\end{array}$ & $\begin{array}{c}5 \\
10 \\
20 \\
30 \\
40\end{array}$ & $\begin{array}{l}13.38 \\
15.58 \\
23.74 \\
27.83 \\
35.92\end{array}$ & $\begin{array}{l}8.12 \\
8.51 \\
9.75 \\
10.8 \\
12.34\end{array}$ & \multicolumn{2}{|r|}{$40>30>20>10>5$} & $<0.01$ & $\begin{array}{l}14.86 \\
15.87 \\
19.82 \\
21.19 \\
24.23\end{array}$ & $\begin{array}{l}5.47 \\
5.12 \\
5.30 \\
5.46 \\
5.96\end{array}$ & $<0.01$ & $40>30>20>10>5$ & $<0.01$ \\
\hline $\begin{array}{c}\mathrm{R}_{\mathrm{EXP}} \\
\left(\mathrm{cm} \mathrm{H} \mathrm{H}_{2} \mathrm{O} \cdot \mathrm{L}^{-1} \cdot \mathrm{s}\right)\end{array}$ & $\begin{array}{c}5 \\
10 \\
20 \\
30 \\
40\end{array}$ & $\begin{array}{l}7.19 \\
7.90 \\
10.56 \\
11.59 \\
13.87\end{array}$ & $\begin{array}{l}2.81 \\
2.81 \\
2.86 \\
2.90 \\
3.12\end{array}$ & \multicolumn{2}{|r|}{$40>30>20>10>5$} & $<0.01$ & $\begin{array}{c}9.14 \\
9.82 \\
12.70 \\
13.54 \\
15.99\end{array}$ & $\begin{array}{l}4.11 \\
3.88 \\
4.27 \\
4.48 \\
5.02\end{array}$ & \multicolumn{2}{|r|}{$40>30>20>10>5$} & $<0.01$ \\
\hline \multicolumn{12}{|c|}{ (b) Restrictive Respiratory System } \\
\hline \multirow{3}{*}{ Variable } & \multirow{3}{*}{$\begin{array}{c}\mathrm{C}_{\mathrm{rs}} \\
\left(\mathrm{L} \cdot \mathrm{cm} \mathrm{H} \mathrm{H}_{2} \mathrm{O}^{-1}\right)\end{array}$} & \multicolumn{5}{|c|}{ VC-CMV } & \multicolumn{5}{|c|}{ PC-CMV } \\
\hline & & \multirow{2}{*}{ Mean } & \multirow{2}{*}{ SD } & \multirow{2}{*}{$p$-Value } & \multirow{2}{*}{ Post Hoc Test } & Linear Trend Analysis & \multirow[b]{2}{*}{ Mean } & \multirow{2}{*}{ SD } & \multirow{2}{*}{$p$-Value } & \multirow{2}{*}{ Post Hoc Test } & Linear Trend Analysis \\
\hline & & & & & & $p$-Value & & & & & $p$-Value \\
\hline $\begin{array}{c}\mathrm{R}_{\mathrm{INSP}} \\
\left(\mathrm{cm} \mathrm{H} \mathrm{H}_{2} \mathrm{O} \cdot \mathrm{L}^{-1} \cdot \mathrm{s}\right)\end{array}$ & $\begin{array}{l}0.01 \\
0.02 \\
0.03 \\
0.04 \\
0.05\end{array}$ & $\begin{array}{l}13.49 \\
13.26 \\
10.37 \\
11.32 \\
11.06\end{array}$ & $\begin{array}{l}9.36 \\
8.75 \\
7.26 \\
7.67 \\
7.70\end{array}$ & $<0.01$ & $\begin{array}{c}<0.01 ;<0.02 \\
<0.01 ;<0.02 ;>0.03 \\
<0.01 ;<0.02 \\
<0.01 ;<0.02 ;<0.03 \\
<0.04 ;<0.05\end{array}$ & $<0.01$ & $\begin{array}{l}12.84 \\
14.01 \\
12.72 \\
13.40 \\
13.21\end{array}$ & $\begin{array}{l}7.72 \\
6.86 \\
5.66 \\
5.39 \\
5.21\end{array}$ & $<0.01$ & $\begin{array}{l}>0.01 \\
<0.02 \\
<0.02\end{array}$ & $<0.01$ \\
\hline $\begin{array}{c}\mathrm{R}_{\mathrm{EXP}} \\
\left(\mathrm{cm} \mathrm{H} \mathrm{H}_{2} \mathrm{O} \cdot \mathrm{L}^{-1} \cdot \mathrm{s}\right)\end{array}$ & $\begin{array}{l}0.01 \\
0.02 \\
0.03 \\
0.04\end{array}$ & $\begin{array}{l}11.58 \\
8.63 \\
6.95 \\
6.88\end{array}$ & $\begin{array}{l}6.03 \\
3.34 \\
2.80 \\
2.88\end{array}$ & $<0.01$ & $\begin{array}{c}<0.01 \\
<0.01 ;<0.02 \\
<0.01 ;<0.02\end{array}$ & $<0.01$ & $\begin{array}{l}9.09 \\
8.30 \\
7.44 \\
8.10\end{array}$ & $\begin{array}{l}3.67 \\
3.36 \\
3.36 \\
3.62\end{array}$ & $<0.01$ & $\begin{array}{c}<0.01 \\
<0.01 ;<0.02 \\
<0.01 ;<0.03\end{array}$ & $<0.01$ \\
\hline & 0.05 & 6.52 & 2.85 & & $\begin{array}{l}<0.01 ;<0.02 ;<0.03 ; \\
<0.04\end{array}$ & & 8.16 & 3.67 & & $<0.01 ;<0.03$ & \\
\hline & 0.08 & 5.41 & 1.97 & & $\begin{array}{l}<0.01 ;<0.02 ;<0.03 ; \\
<0.04 ;<0.05\end{array}$ & & 8.41 & 4.05 & & $<0.01 ;<0.03$ & \\
\hline
\end{tabular}

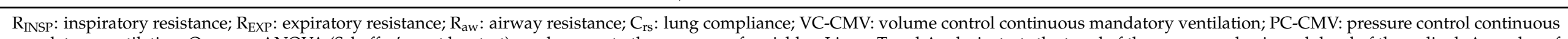

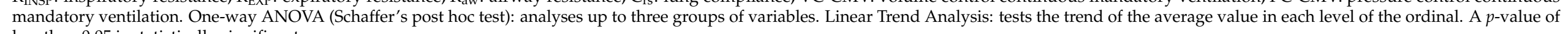
less than 0.05 is statistically significant. 

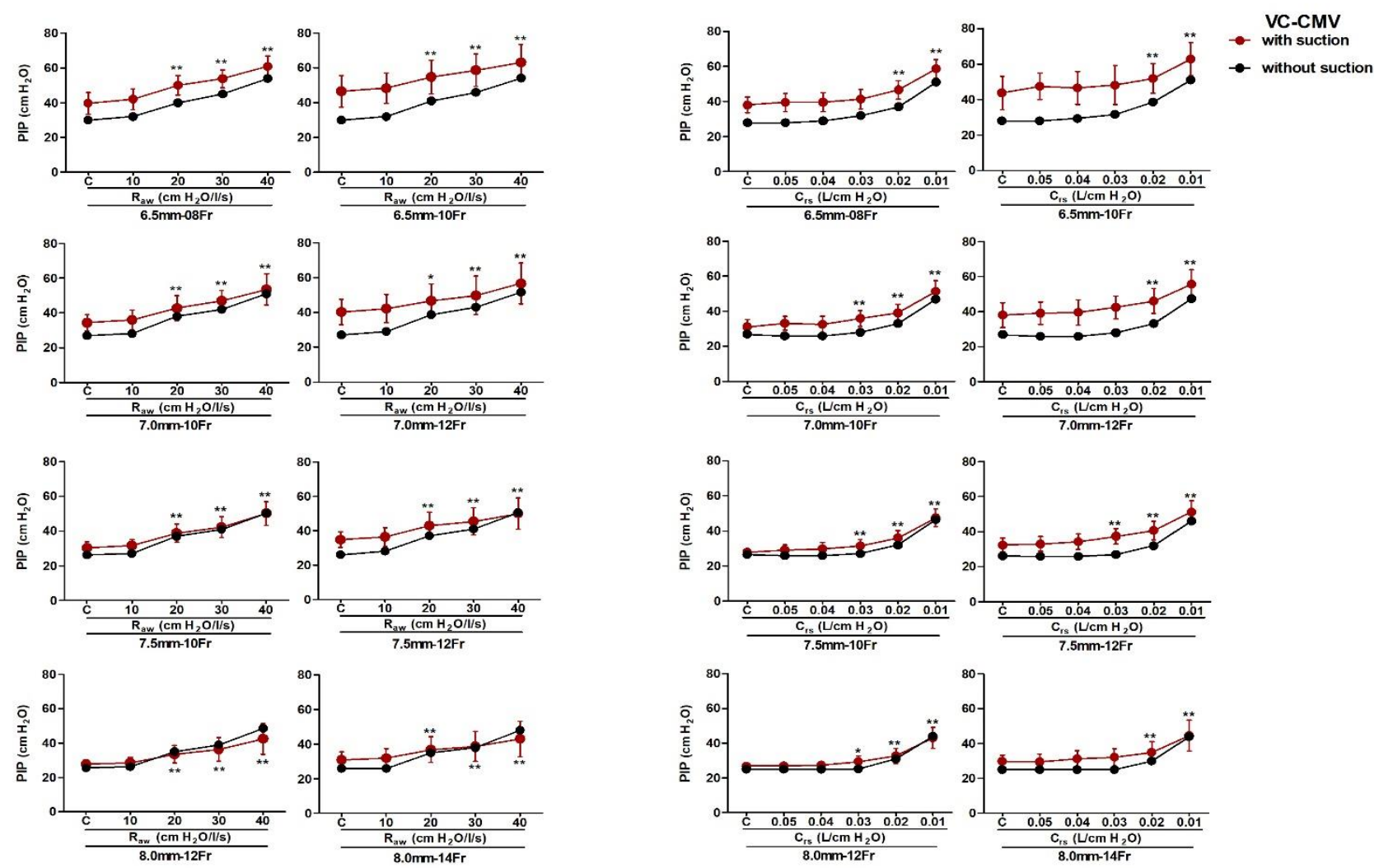

(a)

(b)

Figure 2. Comparison of the change of PIP effects in VC-CMV undergoing closed endotracheal suction: (a) Change of airway resistance and (b) lung compliance of pulmonary mechanics in various ETTs paired with SCs of CSS. C: control ( $0.08 \mathrm{~L} \mathrm{~cm} \mathrm{H}_{2} \mathrm{O}^{-1}$ of $\mathrm{C}_{\mathrm{rs}}$ and $5 \mathrm{~cm} \mathrm{H}_{2} \mathrm{O} \mathrm{L}^{-1}$.s of $\mathrm{R}_{\mathrm{aw}}$ ) group. VC-CMV: volume control continuous mandatory ventilation, this mode is set to $\mathrm{V}_{\mathrm{T}} 0.6 \mathrm{~L}$ with peak flow $60 \mathrm{Lpm}$; PIP: peak inspiratory pressure; $\mathrm{R}_{\mathrm{aw}}$ : airway resistance; $\mathrm{C}_{\mathrm{rs}}$ : lung compliance; ETT: endotracheal tube; SC: suction catheter; $6.5 \mathrm{~mm}-08$ Fr: $6.5 \mathrm{~mm}$ ETT paired with 08 Fr SC, and so on. The closed suctioning procedure was repeated three times. The error bars represent the standard deviation of 30 breaths in each of the pulmonary mechanic scenarios (five airway resistance levels and six lung compliance levels). The independent samples $t$-test was used to compare with the control group. ${ }^{*} p<0.05,{ }^{* *} p<0.01$.

In the obstructive respiratory system (Figure 2a), the PIP level for the pairing of a $6.5 \mathrm{~mm}$ endotracheal tube with $10 \mathrm{Fr} \mathrm{SC}(6.5 \mathrm{~mm}-10 \mathrm{Fr})$ was higher than for the pairing of an $8.0 \mathrm{~mm}$ endotracheal tube with $14 \mathrm{Fr}$ SC $(8.0 \mathrm{~mm}-14 \mathrm{Fr})$. The PIP level rose further with progressive $\mathrm{R}_{\mathrm{aw}}$ pulmonary mechanics. While the distance between the two curves (with suction and without a range) for a $6.5 \mathrm{~mm}$ endotracheal tube was higher than for an $8.0 \mathrm{~mm}$ endotracheal tube, the distance diminished in the case of progressively severe $R_{a w}$. In restrictive respiratory systems, the PIP level rose in line with the decrease in the endotracheal tubes' IDs and compliance levels (Figure 2b). The result indicated that the PIP level was affected by the endotracheal tubes' IDs and the pulmonary mechanics; the severe decline in lung compliance curbed this effect.

\subsubsection{Varied Effects of Ventilation Area on $\triangle \mathrm{PIP} / \mathrm{PIP} \%$ in Both Respiratory Systems}

In the case of obstructive respiratory systems (Figure 3a), it was found that an increase of $\triangle \mathrm{PIP} / \mathrm{PIP} \%$ levels for endotracheal tubes with larger IDs was lower than for endotracheal tubes with smaller IDs. There was a rise of $\triangle \mathrm{PIP} / \mathrm{PIP} \%$ levels for $6.5 \mathrm{~mm}$ $10 \mathrm{Fr}$ and $7.0 \mathrm{~mm}-12 \mathrm{Fr}$ which exceeded $50 \%$, but $\triangle \mathrm{PIP} / \mathrm{PIP} \%$ levels were less than $40 \%$ for $7.5 \mathrm{~mm}-12 \mathrm{Fr}$ and $8.0 \mathrm{~mm}-14 \mathrm{Fr}$ at the $\mathrm{R}_{\mathrm{aw}} 10 \mathrm{~cm} \mathrm{H}_{2} \mathrm{O} \cdot \mathrm{L}^{-1} \cdot \mathrm{s}$. In addition, the change 
of $\triangle \mathrm{PIP} / \mathrm{PIP} \%$ level in suction catheters with larger ODs was more significant than for suction catheters with smaller ODs when paired with the same endotracheal tube. The change was less noticeable in the case of worse $R_{a w}$. Notably, with the use of $8.0 \mathrm{~mm}-12 \mathrm{Fr}$ for closed suctioning, the $\triangle \mathrm{PIP} / \mathrm{PIP} \%$ level dropped to zero or even below zero when $\mathrm{R}_{\mathrm{aw}}$ exceeded $20 \mathrm{~cm} \mathrm{H} \mathrm{H}_{2} \mathrm{O} \cdot \mathrm{L}^{-1} \cdot \mathrm{s}$.
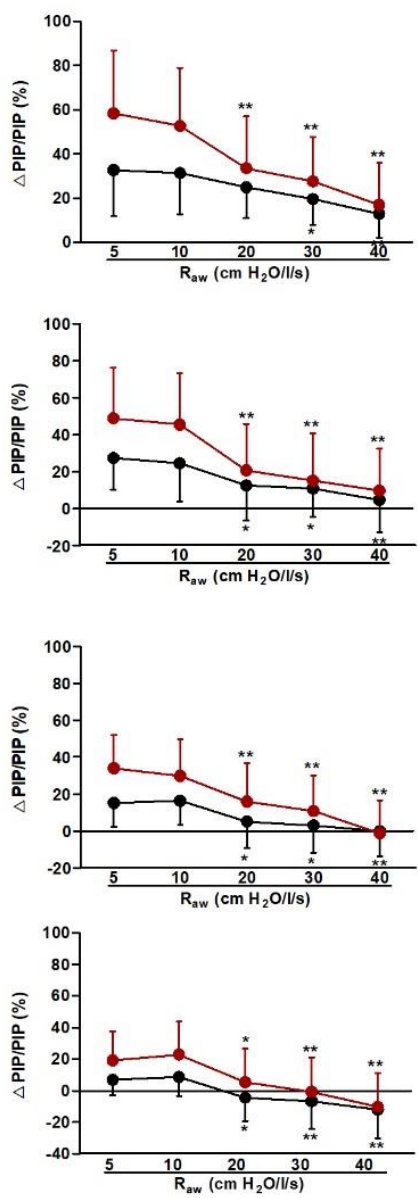

(a)
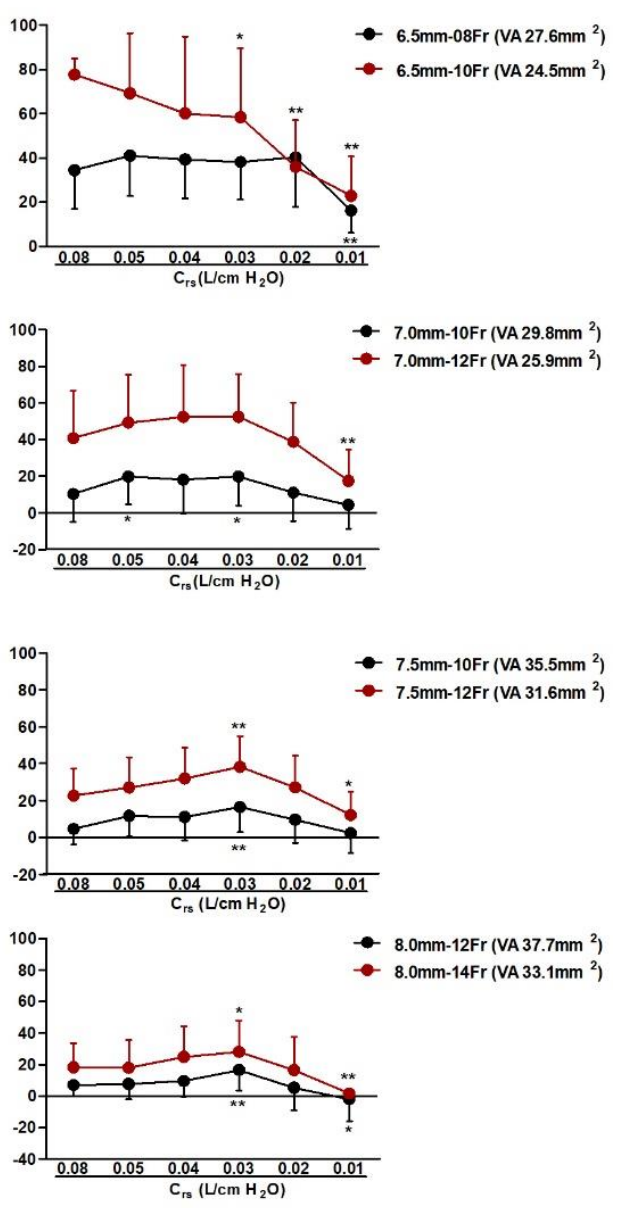

(b)

Figure 3. The effect of the ventilation area on $\triangle \mathrm{PIP} / \mathrm{PIP} \%$ during VC-CMV: (a) Airway resistance of pulmonary mechanics for the obstructive system; (b) Lung compliance of pulmonary mechanics for the restrictive system. $\triangle \mathrm{PIP} / \mathrm{PIP} \%$ decreased for the larger ventilation area and significantly reduced for severe respiratory systems. $\triangle \mathrm{PIP}$ : (delta) suctioning peak inspiratory pressure level substrates a baseline peak inspiratory pressure level; $\triangle \mathrm{PIP} / \mathrm{PIP} \%$ : percentage of PIP (baseline PIP level) divided by $\triangle \mathrm{PIP}$; VC-CMV: volume control continuous mandatory ventilation, this mode is set to VT $0.6 \mathrm{~L}$ with peak flow $60 \mathrm{Lpm}$; $\mathrm{R}_{\mathrm{aw}}$ : airway resistance; $\mathrm{C}_{\mathrm{rs}}$ : lung compliance; ETT: endotracheal tube; $\mathrm{SC}$ : suction catheter; VA: ventilation area (ETT cross-section area minus SC cross-section area); 6.5-08: $6.5 \mathrm{~mm}$ ETT paired with $08 \mathrm{Fr}$ SC, and so on. The independent samples $t$-test was used to compare with $0.08 \mathrm{~L} \cdot \mathrm{cm} \mathrm{H}_{2} \mathrm{O}^{-1}$ of $\mathrm{C}_{\mathrm{rs}}$ and $5 \mathrm{~cm} \mathrm{H}_{2} \mathrm{O} \cdot \mathrm{L}^{-1} \cdot \mathrm{s}$ of $\mathrm{R}_{\mathrm{aw}}$ group. ${ }^{*} p<0.05,{ }^{* *} p<0.01$.

For restrictive respiratory systems (Figure 3b), the experiment showed that an increase in $\triangle \mathrm{PIP} / \mathrm{PIP} \%$ level for endotracheal tubes with smaller IDs was higher than for endotracheal tubes with larger IDs. The $\triangle \mathrm{PIP} / \mathrm{PIP} \%$ level rose over $70 \%$ for $6.5 \mathrm{~mm}-10 \mathrm{Fr}$ but only $20 \%$ for $8.0 \mathrm{~mm}-14 \mathrm{Fr}$ at the $\mathrm{C}_{\mathrm{rs}} 0.05 \mathrm{~L} \cdot \mathrm{cm} \mathrm{H}_{2} \mathrm{O}^{-1}$. In addition, the change of $\triangle \mathrm{PIP} / \mathrm{PIP} \%$ level for suction catheters with larger ODs was less than for suction catheters with smaller ODs for the same endotracheal tube. Moreover, the change of $\triangle \mathrm{PIP} / \mathrm{PIP} \%$ level then dropped to $\mathrm{C}_{\mathrm{rs}} 0.03 \mathrm{~L} \cdot \mathrm{cm} \mathrm{H}_{2} \mathrm{O}^{-1}$. 
Thus, the result indicated that the $\triangle \mathrm{PIP} / \mathrm{PIP} \%$ level rise was associated with usable endotracheal tubes' ventilation area and pulmonary mechanics. The $\triangle \mathrm{PIP} / \mathrm{PIP} \%$ level was more stable during PC-CMV than VC-CMV. The $\triangle \mathrm{PIP} / \mathrm{PIP} \%$ level increased along with a reduction in ventilation area and a decline in pulmonary mechanics. However, this increased level was restricted if $R_{a w}$ was over $20 \mathrm{~cm} \mathrm{H} O \cdot \mathrm{L}^{-1} \cdot \mathrm{s}$ and $\mathrm{C}_{\mathrm{rs}}$ less than $0.03 \mathrm{~L} \cdot \mathrm{cm} \mathrm{H}_{2} \mathrm{O}^{-1}$.

\subsubsection{Analysis of the Impact Factors for $\triangle \mathrm{PIP}$}

Multiple regression analyses were conducted to examine the $\triangle P I P$ level between various potential predictors. The obstructive respiratory system model of the $\triangle \mathrm{PIP}$ level with all four predictors produced $\mathrm{R}^{2}=0.63, p<0.01$ (Table $2 \mathrm{a}$ ). The suction catheter area had a significant positive regression of the $\triangle \mathrm{PIP}$ level, indicating that suction catheters with higher ODs had higher $\triangle P I P$ levels after controlling for the other variables in the model. The endotracheal tube area and $R_{a w}$ had a significant negative regression of the $\triangle \mathrm{PIP}$ level, indicating that the higher endotracheal tube areas and $\mathrm{R}_{\mathrm{aw}}$ had lower $\triangle \mathrm{PIP}$ levels after accounting for the suction catheter area. The $\triangle P I P$ levels impacted in the VC-CMV mode more than in the PC-CMV.

Table 2. Multiple regression analysis of factors affecting closed endotracheal suctioning: (a) Ventilator-related parameters of factors affecting the obstructive respiratory system; (b) Ventilator-related parameters of factors affecting the restrictive respiratory system.

(a) Obstructive Respiratory System Model

\begin{tabular}{|c|c|c|c|c|c|c|c|c|c|}
\hline & \multicolumn{3}{|c|}{$\triangle \mathrm{PIP}\left(\mathrm{cm} \mathrm{H} \mathrm{H}_{2} \mathrm{O}\right)$} & \multicolumn{3}{|c|}{$\triangle \mathrm{PEEP}\left(\mathrm{cm} \mathrm{H} \mathrm{H}_{2} \mathrm{O}\right)$} & \multicolumn{3}{|c|}{$\triangle \operatorname{Vexp}(\mathrm{L})$} \\
\hline & B & SE & $t$ & B & SE & $t$ & B & SE & $t$ \\
\hline Constant & 22.64 & 2.09 & $10.84^{* *}$ & -0.52 & 0.38 & -1.34 & 1.50 & 0.34 & $4.38^{* *}$ \\
\hline ETT area $\left(\mathrm{mm}^{2}\right)$ & -0.42 & 0.05 & $-7.36^{* *}$ & 0.00 & 0.01 & 0.19 & -0.03 & 0.01 & $-3.48 * *$ \\
\hline $\mathrm{SC}$ area $\left(\mathrm{mm}^{2}\right)$ & 0.24 & 0.12 & $2.09 *$ & 0.07 & 0.02 & $3.40 *$ & 0.26 & 0.02 & $13.52 * *$ \\
\hline $\mathrm{R}_{\mathrm{aw}}\left(\mathrm{cm} \mathrm{H}_{2} \mathrm{OL} \mathrm{L}^{-1} \mathrm{~s}\right)$ & -0.10 & 0.02 & $-4.19 * *$ & 0.00 & 0.00 & 0.73 & -0.02 & 0.00 & $-4.49 * *$ \\
\hline Mode & -4.86 & 0.61 & $-7.95^{* *}$ & -0.05 & 0.11 & -0.42 & 1.03 & 0.10 & 10.31 ** \\
\hline $\mathrm{R}^{2}$ & & 0.63 & & & 0.13 & & & 0.79 & \\
\hline$p$ & & $<0.01$ & & & 0.04 & & & $<0.01$ & \\
\hline
\end{tabular}

(b) Restrictive Respiratory System Model

\begin{tabular}{|c|c|c|c|c|c|c|c|c|c|}
\hline & \multicolumn{3}{|c|}{$\triangle \mathrm{PIP}\left(\mathrm{cm} \mathrm{H}_{2} \mathrm{O}\right)$} & \multicolumn{3}{|c|}{$\triangle P E E P\left(\mathrm{~cm} \mathrm{H}_{2} \mathrm{O}\right)$} & \multicolumn{3}{|c|}{$\triangle \operatorname{Vexp}(\mathrm{L})$} \\
\hline & B & SE & $t$ & B & SE & $t$ & B & SE & $t$ \\
\hline Constant & 21.75 & 1.86 & $11.69 * *$ & -0.34 & 0.30 & -1.16 & -0.68 & 0.64 & -1.04 \\
\hline ETT area $\left(\mathrm{mm}^{2}\right)$ & -0.49 & 0.05 & $-9.48^{* *}$ & 0.00 & 0.01 & 0.42 & -0.05 & 0.02 & $-2.56 *$ \\
\hline $\mathrm{SC}$ area $\left(\mathrm{mm}^{2}\right)$ & 0.47 & 0.11 & $4.47^{* *}$ & 0.06 & 0.17 & $3.84^{* *}$ & 0.32 & 0.04 & $8.63 * *$ \\
\hline $\mathrm{C}_{\mathrm{rs}}\left(\mathrm{L} \mathrm{cm} \mathrm{H}_{2} \mathrm{O}^{-1}\right)$ & 22.98 & 11.99 & 1.92 & -5.19 & 1.96 & $-2.65^{* *}$ & 39.15 & 4.15 & $9.42 * *$ \\
\hline Mode & -7.35 & 0.54 & $-13.52 * *$ & -0.09 & 0.09 & -1.07 & 1.42 & 0.19 & $7.52 * *$ \\
\hline $\mathrm{R}^{2}$ & & 0.72 & & & 0.23 & & & 0.68 & \\
\hline$p$ & & $<0.01$ & & & $<0.01$ & & & $<0.01$ & \\
\hline
\end{tabular}

$\triangle$ : delta (a variation level that the suctioning PIP, PEEP, and Vexp level subtract at baseline level); $\triangle$ PIP: delta peak inspiratory pressure; $\triangle$ Vexp: delta expiratory minute volume; $\triangle$ PEEP: delta positive end-expiratory pressure; ETT area: endotracheal tube cross-section area. SC area: suction catheter cross-section area; $\mathrm{C}_{\mathrm{rs}}$ : lung compliance; $\mathrm{R}_{\mathrm{aw}}$ : airway resistance; Mode: VC-CMV (volume control continuous mandatory ventilation); PC-CMV (pressure control continuous mandatory ventilation). B: unstandardized regression coefficient; SE: standard error; $t=t$ statistic, which evaluates the predictor; $\mathrm{R}^{2}$ : adjusted R-squared; mode of VC-CMV dummy variable is 0 . The mode of the PC-CMV dummy variable is $1 .{ }^{*} p<0.05,{ }^{* *} p<0.01$.

Moreover, the restrictive respiratory system model of the $\triangle \mathrm{PIP}$ level with all four predictors produced $\mathrm{R}^{2}=0.72, p<0.01$. As can be seen in Table $2 \mathrm{~b}$, the suction catheter area had a significant positive regression of the $\triangle P I P$ level, indicating that suction catheters with higher ODs had higher $\triangle P I P$ levels after controlling for the other variables in the model. The endotracheal tube area had a significant negative regression of the $\triangle \mathrm{PIP}$ level, indicating that after accounting for the suction catheter area, the higher endotracheal tube areas had lower $\triangle$ PIP levels. The $\mathrm{C}_{\mathrm{rs}}$ did not contribute to the multiple regression model.

\subsection{Varied Effects of ETT and SC on PEEP in Both Respiratory Systems}

A closed suctioning system usually can be connected to a ventilator during suctioning in patients with deteriorating respiratory systems to maintain higher PEEP. The experiment 
showed that PEEP levels for $6.5 \mathrm{~mm}$ and $7.0 \mathrm{~mm}$ were similar to $7.5 \mathrm{~mm}$ endotracheal tubes with suction catheters that could be kept at the set scale during closed suction in both ventilation modes (Figure 4). In the $8.0 \mathrm{~mm}$ endotracheal tube with a $12 \mathrm{Fr}$ suction catheter, PEEP levels began to experience a slight variation in both pulmonary mechanics. However, with the 14 Fr suction catheter, the PEEP level demonstrated a rising trend (as an intrinsic PEEP) during PC-CMV if $\mathrm{R}_{\mathrm{aw}}$ increased to $40 \mathrm{~cm} \mathrm{H}_{2} \mathrm{O} \cdot \mathrm{L}^{-1}$ (Figure 4a). These changes did not appear in the severely restrictive system (Figure $4 \mathrm{~b}$ ). In contrast, VC-CMV with the 14 Fr suction catheter showed a significant reduction in PEEP level during closed suctioning.
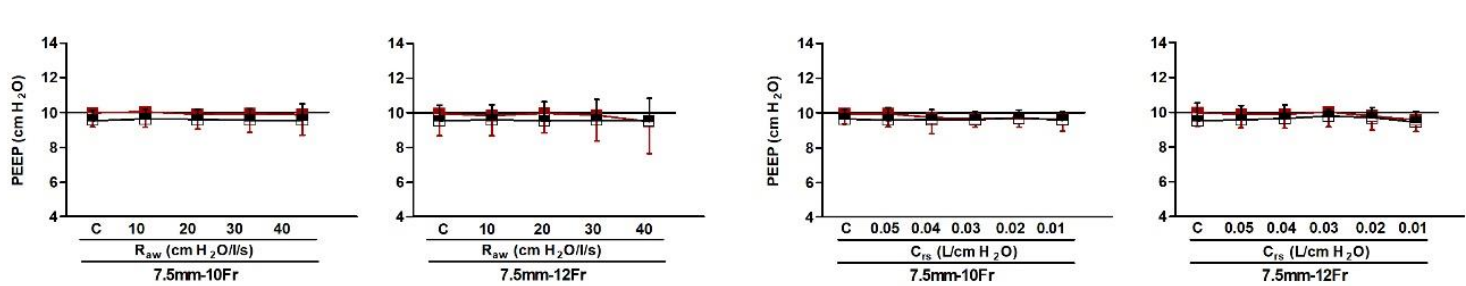

- VC-CMV
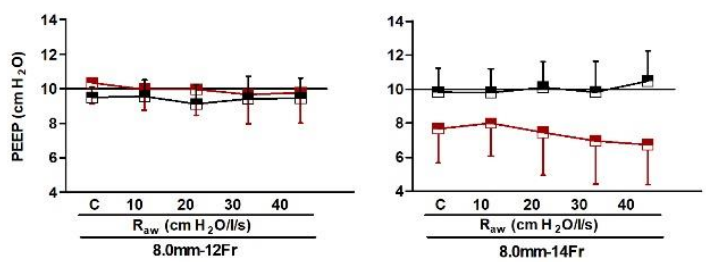

(a)
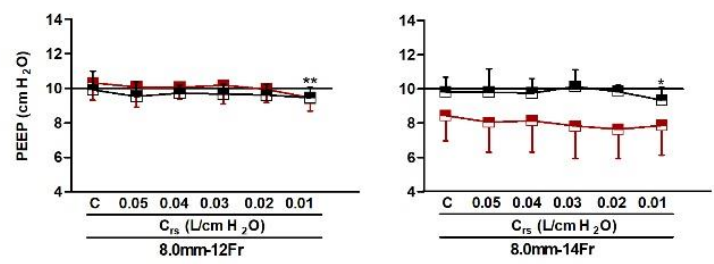

(b)

Figure 4. The effects of $7.5 \mathrm{~mm}$ and $8.0 \mathrm{~mm}$ ETT with $10 \mathrm{Fr}, 12 \mathrm{Fr}$, and $14 \mathrm{Fr}$ SC on PEEP in different respiratory systems: (a) Changes in airway resistance of pulmonary mechanics for the obstructive system; (b) Changes in lung compliance of pulmonary mechanics for the restrictive system in VC-CMV and PC-CMV. PC-CMV: pressure control continuous mandatory ventilation, this mode set inspiratory pressure at $20 \mathrm{~cm} \mathrm{H}_{2} \mathrm{O}$ with inspiratory time at $1 \mathrm{sec}$; VC-CMV: volume control continuous mandatory ventilation, this mode is set to VT $0.6 \mathrm{~L}$ with peak flow $60 \mathrm{Lpm}$; C: control group $\left(0.08 \mathrm{~L} \mathrm{~cm} \mathrm{H}_{2} \mathrm{O}^{-1}\right.$

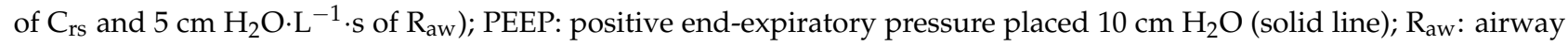
resistance; $\mathrm{C}_{\mathrm{rs}}$ : lung compliance; ETT: endotracheal tube; $\mathrm{SC}$ : suction catheter; $7.5 \mathrm{~mm}-10 \mathrm{Fr}$ : $7.5 \mathrm{~mm}$ ETT paired with $10 \mathrm{Fr}$ $\mathrm{SC}$, and so on. The closed suctioning procedure was repeated three times. The error bars represent the standard deviation of 30 breaths in each of the pulmonary mechanic scenarios (five airway resistance levels and six lung compliance levels). The independent samples $t$-test was used to compare with the control group. ${ }^{*} p<0.05,{ }^{* *} p<0.01$.

Analysis of the Impact Factors for $\triangle$ PEEP

The obstructive respiratory system model of $\triangle \mathrm{PEEP}$ with all four predictors produced $\mathrm{R}^{2}=0.13, p=0.04$. As can be seen in Table $2 \mathrm{a}$, the only suction catheter area had a significant positive regression $\triangle \mathrm{PEEP}$ level, indicating that suction catheters with higher ODs had higher $\triangle$ PEEP levels. Endotracheal tube area, $R_{a w}$, and mode did not contribute to the multiple regression model.

The restrictive respiratory system model of the $\triangle \mathrm{PEEP}$ level with all four predictors produced $\mathrm{R}^{2}=0.23, p<0.01$ (Table $2 \mathrm{~b}$ ). The suction catheter area had a significant positive regression $\triangle P E E P$ level, indicating that suction catheters with higher ODs had higher $\triangle$ PEEP levels after controlling for the other variables in the model. The $C_{\mathrm{rs}}$ had a significant negative $\triangle \mathrm{PEEP}$ level, indicating that higher $\mathrm{C}_{\mathrm{rs}}$ had lower $\triangle \mathrm{PEEP}$ levels after accounting for the suction catheter area. Endotracheal tube area and mode did not contribute to the multiple regression models.

\subsection{Varied Effects of ETT and SC on Vexp in Both Types of Respiratory Systems}

Closed endotracheal suctioning significantly reduced lung volume loss by handling the suctioning procedure in terms of suctioning pressure and time. The study examined the expiratory minute volume (Vexp) and the control of suction pressure time. Figure 5 
shows that the Vexp level decreased in both progressively declining respiratory systems during PC-CMV. The distance between the Vexp curves of VC-CMV and PC-CMV with a $6.5 \mathrm{~mm}$ endotracheal tube was less than with an $8.0 \mathrm{~mm}$ endotracheal tube. Moreover, the distance between the two curves with the restrictive respiratory system was less than with the obstructive respiratory system.
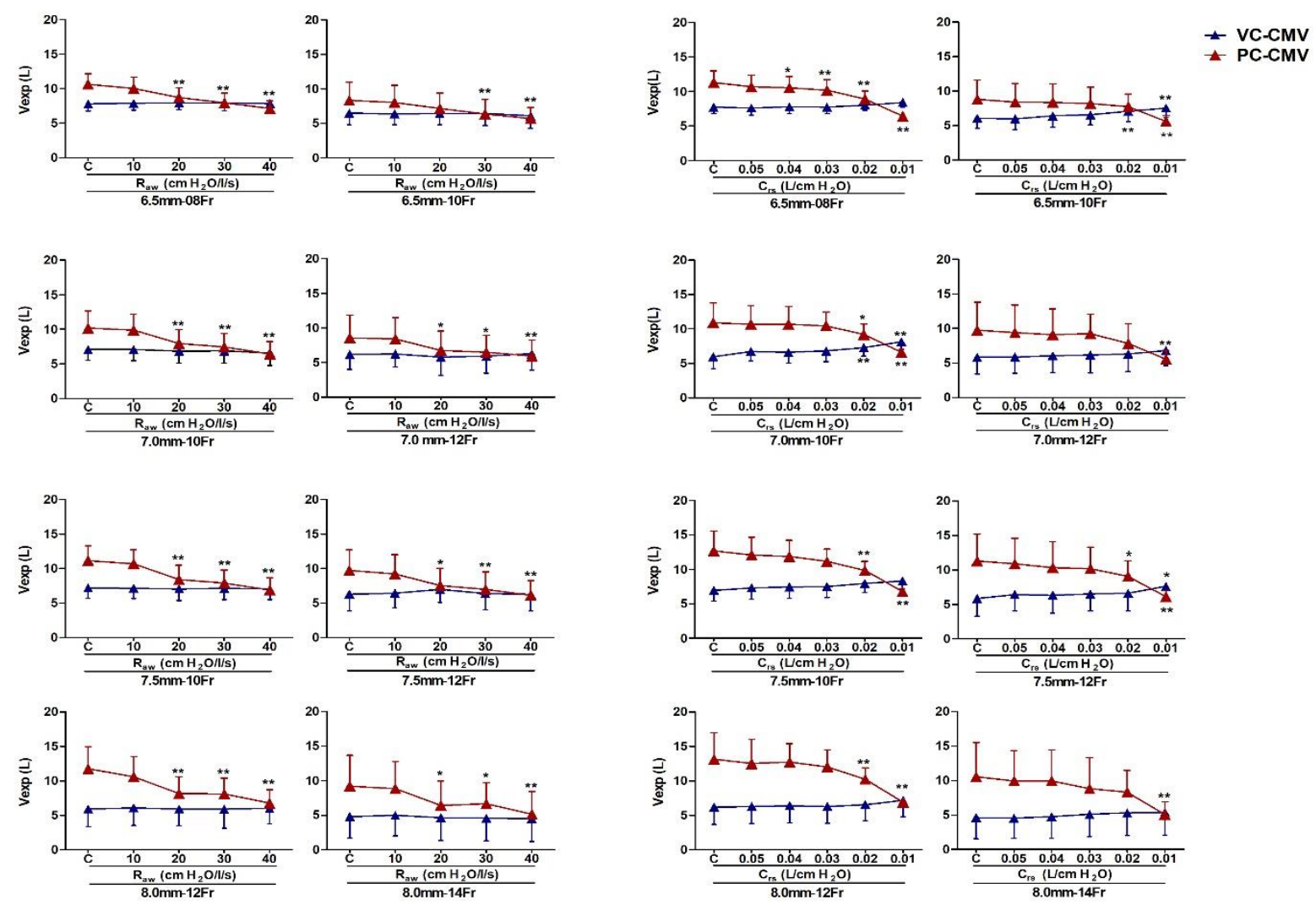

(a)
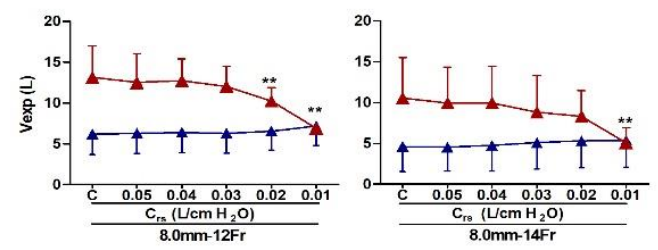

(b)

Figure 5. Comparison of the changes in Vexp effects in different respiratory systems and ventilation modes. Various ETTs paired with SCs for CSS conducted endotracheal suctioning in airway resistance of pulmonary mechanics for the obstructive system (a) and lung compliance of pulmonary mechanics for the restrictive system (b) with VC-CMV or PC-CMV. PC-CMV: pressure control continuous mandatory ventilation, this mode set inspiratory pressure at $20 \mathrm{~cm} \mathrm{H}_{2} \mathrm{O}$ with inspiratory time at $1 \mathrm{sec}$; VC-CMV: volume control continuous mandatory ventilation, this mode is set to VT $0.6 \mathrm{~L}$ with peak flow $60 \mathrm{Lpm}$; $\mathrm{C}$ : control group $\left(0.08 \mathrm{~L} \cdot \mathrm{cm} \mathrm{H}_{2} \mathrm{O}^{-1}\right.$ of $\mathrm{C}_{\mathrm{rs}}$ and $5 \mathrm{~cm} \mathrm{H} \mathrm{H}_{2} \mathrm{O} \cdot \mathrm{L}^{-1} \cdot \mathrm{s}$ of $\left.\mathrm{R}_{\mathrm{aw}}\right)$; Vexp: expiratory minute volume; $\mathrm{R}_{\mathrm{aw}}$ : airway resistance; $\mathrm{C}_{\mathrm{rs}}$ : lung compliance; ETT: endotracheal tube; $\mathrm{SC}$ : suction catheter; $6.5 \mathrm{~mm}-08 \mathrm{Fr}$ : $6.5 \mathrm{~mm}$ ETT paired with $08 \mathrm{Fr}$ $\mathrm{SC}$, and so on. The closed suctioning procedure was repeated three times. The error bars represent the standard deviation of 30 breaths in each of the pulmonary mechanic scenarios (five airway resistance levels and six lung compliance levels). The independent samples $t$-test was used to compare with the control group. ${ }^{*} p<0.05,{ }^{* *} p<0.01$.

In the obstructive respiratory system (Figure 5a), the Vexp level in lower $R_{a w}$ was higher than in higher $\mathrm{R}_{\mathrm{aw}}$ during PC-CMV. The distance between the two curves (VC-CMV and PC-CMV) of Vexp had a more extensive range for lower $R_{a w}$. However, the curve distance diminished when $\mathrm{R}_{\mathrm{aw}}$ exceeded $20 \mathrm{~cm}, \mathrm{H}_{2} \mathrm{O} \cdot \mathrm{s} \cdot \mathrm{L}^{-1}$ of. In the restrictive respiratory system (Figure 5b), the Vexp level was higher in higher $C_{r s}$ than lower $C_{r s}$ during PC-CMV. In addition, the distance between the two curves in Vexp increased in line with the rise of $\mathrm{C}_{\mathrm{rs}}$, but the two curves began descending along with the $\mathrm{C}_{\mathrm{rs}}$ progressive decline to $0.02 \mathrm{~L} \cdot \mathrm{cm} \mathrm{H}_{2} \mathrm{O}^{-1}$. When the $\mathrm{C}_{\mathrm{rs}}$ decreased to $0.01 \mathrm{~L} \cdot \mathrm{cm} \mathrm{H}_{2} \mathrm{O}^{-1}$, the Vexp of PC-CMV was equal to that of VC-CMV. 


\subsubsection{Varied Effects of ETTs and SCs on $\triangle$ Vexp/Vexp\% in Both Types of Respiratory} Systems

This study examined the change of Vexp percentage ( $\triangle$ Vexp/Vexp $\%)$ levels in different ventilation modes and pulmonary mechanics during closed suctioning (Figure 6). In the case of obstructive respiratory systems (Figure $6 \mathrm{a}$ ), $\triangle$ Vexp/Vexp\% levels for $8.0 \mathrm{~mm}-14 \mathrm{Fr}$ were higher than $6.5 \mathrm{~mm}-08 \mathrm{Fr}(40 \%$ versus $20 \%)$. The levels were also higher for suction catheters with larger ODs than those with smaller ODs with the same endotracheal tube. However, the $\triangle$ Vexp/Vexp\% level showed no significant difference in $R_{a w}$ 's progressive rising, and the $\triangle \operatorname{Vexp} / \mathrm{Vexp} \%$ of the curve distance showed no apparent distinction during CSS.
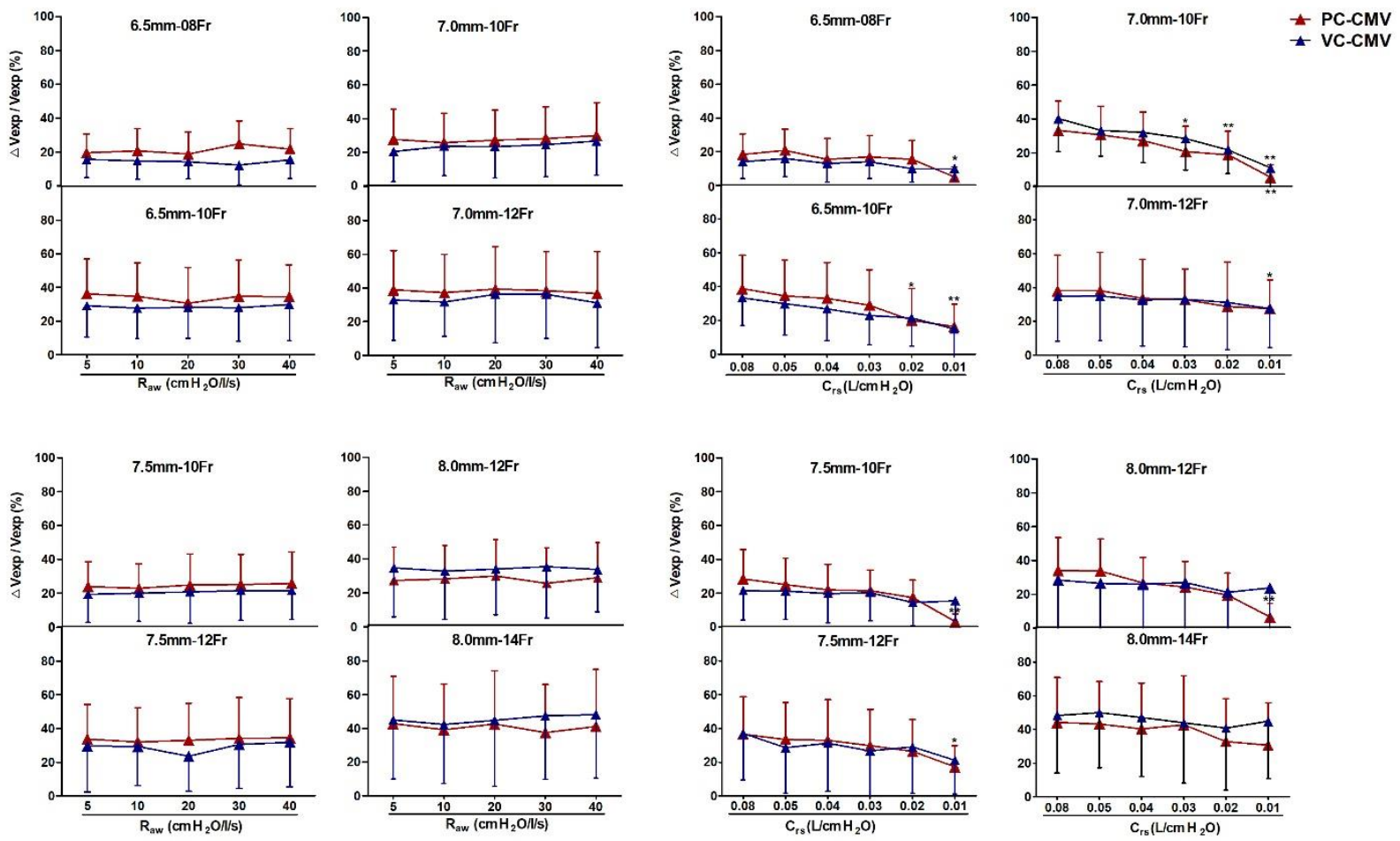

(a)

(b)

Figure 6. Comparison of $\triangle$ Vexp/Vexp\% effects in different respiratory systems and ventilation modes. Various ETTs paired with SCs for CSS conducted endotracheal suctioning in airway resistance pulmonary mechanics for the obstructive system (a) and lung compliance pulmonary mechanics for the restrictive system (b) with VC-CMV or PC-CMV. ( $\triangle$ ) Vexp: (delta) expiratory minute volume (baseline Vexp level substrates with suctioning Vexp level); $\triangle$ Vexp/Vexp\%: percentage of baseline Vexp level divided by $\triangle$ Vexp; PC-CMV: pressure control continuous mandatory ventilation, this mode set inspiratory pressure at $20 \mathrm{~cm} \mathrm{H}_{2} \mathrm{O}$ with inspiratory time at $1 \mathrm{~s}$; VC-CMV: volume control continuous mandatory ventilation, this mode is set to $\mathrm{V}_{\mathrm{T}} 0.6 \mathrm{~L}$ with peak flow $60 \mathrm{Lpm} ; \mathrm{R}_{\mathrm{aw}}$ : airway resistance; $\mathrm{C}_{\mathrm{rs}}$ : lung compliance; ETT: endotracheal tube; SC: suction catheter; $6.5 \mathrm{~mm}-08 \mathrm{Fr}: 6.5 \mathrm{~mm}$ ETT paired with $08 \mathrm{Fr}$ SC, and so on. The independent samples $t$-test was used to compare with $5 \mathrm{~cm} \mathrm{H} \mathrm{H}_{2} \mathrm{O} \cdot \mathrm{L}^{-1} \cdot \mathrm{s}$ of $\mathrm{R}_{\mathrm{aw}}$ and $0.08 \mathrm{~L} \cdot \mathrm{cm} \mathrm{H}_{2} \mathrm{O}^{-1}$ of $\mathrm{C}_{\mathrm{rs}}$ group. ${ }^{*} p<0.05$, ${ }^{* *} p<0.01$.

Thus, for restrictive respiratory systems (Figure $6 \mathrm{~b}$ ), the $\triangle \mathrm{Vexp} / \mathrm{Vexp} \%$ level exhibited a declining trend along with a progressive reduction of $\mathrm{C}_{\mathrm{rs}}$. The $\triangle \mathrm{Vexp} / \mathrm{Vexp} \%$ levels for $8.0 \mathrm{~mm}-14 \mathrm{Fr}$ were higher than for $6.5 \mathrm{~mm}-08 \mathrm{Fr}(40 \%$ versus $20 \%)$ during PC-CMV. The levels were also higher for suction catheters with larger ODs than those with smaller ODs with the same endotracheal tubes. In contrast, there was a difference in the $\triangle \mathrm{Vexp} / \mathrm{Vexp} \%$ of the curve distance only for $6.5 \mathrm{~mm}-08$ Fr. Furthermore, no significant correlation was found between $\triangle$ Vexp/Vexp $\%$ levels and VC-CMV, except for $7.0 \mathrm{~mm}-10 \mathrm{Fr}$. The $\triangle$ Vexp/Vexp\% levels reduced considerably at $\mathrm{C}_{\mathrm{rs}}$ of $0.01 \mathrm{~L} \cdot \mathrm{cm} \mathrm{H}_{2} \mathrm{O}^{-1}$ during PC-CMV. 


\subsubsection{Analysis of the Factors Affecting $\triangle$ Vexp}

The obstructive respiratory system model of $\triangle$ Vexp levels with all four predictors produced $\mathrm{R}^{2}=0.79, p<0.01$ (Table $2 \mathrm{a}$ ). The suction catheter area had a significant positive regression $\triangle$ Vexp level, indicating that suction catheters with higher ODs had higher $\triangle$ Vexp levels. The endotracheal tube area and $R_{a w}$ had a significant negative regression $\triangle$ Vexp level. After accounting for the suction catheter area, those with a higher endotracheal tube area and $R_{a w}$ had lower $\triangle$ Vexp levels. The $\triangle$ Vexp level was impacted in PC-CMV mode more than VC-CMV mode.

The restrictive respiratory system model of $\triangle$ Vexp level with all four predictors produced $\mathrm{R}^{2}=0.68, p<0.01$. As can be seen in Table $2 \mathrm{~b}$, the suction catheter area and $\mathrm{C}_{\mathrm{rs}}$ had a significant positive regression $\triangle$ Vexp level, indicating that suction catheters with higher ODs and $C_{\mathrm{rs}}$ had higher $\triangle$ Vexp levels after controlling for the other variables in the model. The endotracheal tube area had a significant negative regression $\triangle$ Vexp level, indicating that after accounting for the suction catheter area and $\mathrm{C}_{\mathrm{rs}}$, the higher endotracheal tube area had lower $\triangle$ Vexp levels. The $\triangle$ Vexp level was impacted in PCCMV mode more than VC-CMV mode.

\section{Discussion}

This study examined the effects of ventilator-related parameters during closed endotracheal suctioning; even CSS used for $15 \mathrm{~s}$ of suctioning had advantages in clinical practice. The study found that CSS of endotracheal suction caused increased respiratory resistance $\left(\mathrm{R}_{\mathrm{INSP}}\right.$ and $\left.\mathrm{R}_{\mathrm{EXP}}\right)$, mainly due to the effects of positive pressure ventilation, suction catheter insertion into endotracheal tubes, and patients' pulmonary mechanics. VC-CMV offers a pre-set tidal volume and minute ventilation safety. It also requires set inspiratory flow, flow waveform, and inspiratory time for delivering tidal volume. However, airway pressure increases in response to reduced lung compliance or increased airway resistance during VCV-CMV. In PC-CMV, the ventilator provides a high inspiratory flow rate to achieve the pre-set pressure and time during the inspiration phase. However, tidal volume is dependent on the pulmonary mechanics.

Additionally, $R_{a w}$ is the opposition to flow caused by the forces of friction. It is usually defined as the ratio of driving pressure to the airflow rate during the mechanical ventilation, $\mathrm{R}_{\mathrm{aw}}=\Delta \mathrm{P} /$ Flow $(\Delta \mathrm{P}$ is the pressure applied to the airway above PEEP). Expiratory flow is normally passive and is determined by alveolar pressure, as well as $R_{a w}$, the elapsed time since initiation of exhalation, and constant time. Lung units with higher resistance and/or compliance will have a longer time constant and require more time to fill and empty. End-expiratory flow is limited if $R_{a w}$ is high and expiratory time is not sufficient, indicating the presence of air trapping (auto-PEEP).

The rise in PIP is a significant ventilator-related parameter during VC-CMV with closed suction. It is a phenomenon that can be aggravated when the pulmonary mechanics of the respiratory system was compromised. PEEP changed in 14 Fr SC of CSS, with a more significant reduction in VC-CMV than in PC-CMV. PEEP was at an increased level in severely $R_{a w}$ pulmonary mechanics during PC-CMV, but a decreased level was found in severely $\mathrm{C}_{\mathrm{rs}}$ pulmonary mechanics. Additionally, minute volume was a critical ventilatorrelated parameter in PC-CMV. The change of Vexp was associated with larger ODs of suction catheters and with pulmonary mechanics. The amount of the decrease in Vexp reduced in severely $\mathrm{C}_{\mathrm{rs}}$ pulmonary mechanics.

The study shows that a change of $\triangle \mathrm{PIP} \%$ during VC-CMV hinges on the ventilation area of the endotracheal tubes. For instance, the change of $\triangle \mathrm{PIP} \%$ for a $12 \mathrm{Fr}$ suction catheter paired with a $7.0 \mathrm{~mm}$ endotracheal tube was greater than for an $8.0 \mathrm{~mm}$ endotracheal tube $(50 \%$ versus $30 \%)$ in $0.03 \mathrm{~L} \cdot \mathrm{cm} \mathrm{H}_{2} \mathrm{O}^{-1}$ of $\mathrm{C}_{\mathrm{rs}}$. These results were consistent with a previous cardiac surgery study, which showed that the airway pressure in volumecontrolled mode peaks when the insertion of $14 \mathrm{Fr}$ SC into an endotracheal tube reaches an $8.0 \mathrm{~mm}$ depth position [21]. This earlier research pointed to changes in the radius of 
the tube, which had a significant effect on resistance [22]. Due to this higher resistance, a ventilator needs more energy (positive pressure) to expand the lungs [23-25].

A previous bench study put forth an alternative solution for pairing suction catheters with endotracheal tubes, suggesting a volume or area ratio of SC/ETT $50 \%$, in correspondence with a diameter ratio of $70 \%$ SC/ETT ratio [26]. Clinical studies have associated $R_{a w}$ 's rise in CSS with a practice-related factor and the effect of the reduced area of the artificial airway tube $[27,28]$. When closed suction was underway for patients with a progressive decline in pulmonary mechanics with VC-CMV, PIP rose more significantly. In addition, a higher PIP resulting from higher trans-airway pressure can cause barotrauma to the detriment of the lung, especially for patients with COPD $[8,29]$. A study on animals found that histopathologic changes in the lung with a tidal volume of $15 \mathrm{~mL} / \mathrm{kg}$ induced a PIP of $40 \mathrm{~cm} \mathrm{H}_{2} \mathrm{O}$ for up to $32 \mathrm{~h}$ [30]. Unlike other research carried out in this area, we find a significant difference in PIP according to the endotracheal tube's ventilation area and pulmonary mechanics during closed suction with different modes. The optimal OD of suction catheters can be extended to the ventilation area; this is critical for the efficacy and effectiveness of PIP management during closed endotracheal suctioning. Using PC-CMV mode can avoid raising transpulmonary pressure during closed suction. A maximum airway pressure alarm was set in advance for barotrauma incidents through a higher PIP in patients with deteriorating pulmonary mechanics.

A higher PEEP level (intrinsic PEEP) than the set level was observed in severe $R_{a w}$ cases during PC-CMV. PC-CMV is advantageous since the operator can control inspiratory pressure ventilation directly. During suctioning, the inspiratory pressure decreased significantly with a $14 \mathrm{Fr}$ suction catheter in CSS. The ventilator has to provide extra flow to compensate for the loss of inspiratory pressure in PC-CMV. The PEEP level in breathing circuits rose when the inflow volume exceeded gas outflow during catheter suction. Our study demonstrates that in the obstructive respiratory system, when undergoing PC-CMV with closed suction, the rise of $R_{a w}$ may worsen, resulting in an intrinsic PEEP effect. In the clinical setting, for COPD patients with dynamic hyperinflation, it is necessary to generate high pleural pressure swings for patients undertaking mechanical ventilation to a level higher than intrinsic PEEP before triggering the activation of the ventilator [31,32]. However, the ventilator will be ineffective for this triggering function if patients have a weakness in fatigue of the respiratory muscle [33]. New monitoring waveform systems can be used with other inputs, helping detection and improving triggering synchrony management. These results show that careful attention must be paid to the PEEP level when obstructive respiratory system patients are undergoing closed suction.

PEEP levels decreased significantly for $14 \mathrm{Fr}$ of SC in VC-CMV, a PEEP level lower than the set level observed for the severe $\mathrm{C}_{\mathrm{rs}}$ pulmonary mechanics during PC-CMV. This PEEP effect was at odds with the results of previous studies. A prior review of CSS's effectiveness shows that the prevention of lung collapse can be helped by performing suction without interrupting mechanical ventilation to maintain PEEP [7]. In this way, the decline of $\mathrm{PaO}_{2}$ in mechanical ventilation patients can be improved $[4,17,34,35]$. There is a possible explanation for the result in this study: $14 \mathrm{Fr}$ SC has a higher cross-section area conducive to removing more airflow in the airway, especially in VC-CMV, which can control the tidal volume. It can thus be reasonably assumed that VC-CMV with less than 14 Fr CSS or PC-CMV was applied to patients with high PEEP to preserve more alveoli volume during suction at the end of expiration.

Approximately $5 \%$ of patients with COVID-19 eventually develop ARDS, septic shock, and/or multiple organ failure. The mainstay of clinical treatment for patients with respiratory failure is mechanical ventilation [36]. CSS can decrease the clinical signs of hypoxemia by creating a small volume loss to preserve PEEP. It can also be used during suction to limit the spread of Severe Acute Respiratory Syndrome Coronavirus 2 into the environment, and contamination of the person during suction [37]. Therefore, there are significant advantages to the clinical practitioner adopting CSS for critically ill patients with COVID-19. 
This study found that the conserved ventilation volume was affected by the OD size of suction catheters in PC-CMV. Vexp decreased with suction catheters with larger ODs, but this was less noticeable when respiratory systems were severe. A previous clinical study has shown that a steady tidal volume in the lung is positively correlated with improved oxygenation during suctioning [38]. A randomized clinical study observed an immediately decreased $\mathrm{V}_{\mathrm{T}}$, but that minute volume was maintained during closed endotracheal suctioning [39]. Additionally, a lung injury animal model proved closed suction only protected against derecruitment when a small catheter is used, especially in the nondependent lung [40]. An electrical impedance tomography can be used to examine lung volume during CSS cleaning. The presence of a valve CSS should be considered essential in preserving lung volume and uninterrupted ventilation in mechanically ventilated patients [41]. However, a randomized study in post-cardiac surgery patients demonstrated that closed suctioning minimized lung volume loss during suctioning but counterintuitively resulted in a slower recovery of end-expiratory lung volume post suction than open suction [42]. Finally, the performance of the recruitment maneuver after either suction method has been recognized to be beneficial in restoring end-expiratory lung volume [6,42].

The advantage of VC-CMV lies in the ability to control tidal volume and minute ventilation. During endotracheal suctioning, two crucial factors can cause unexpected volume loss. The first is a potential higher negative pressure if the suction flow exceeds ventilation or if the secretions are lining the inside surface of the tube [43]. The second is the compression ratio that equals the gas volume compressed per pressure $\left(\mathrm{cm} \mathrm{H}_{2} \mathrm{O}\right)$ of PIP in a breathing circuit. The compression ratio values ranged from 0.3 to $4.5 \mathrm{~mL} / \mathrm{cm} \mathrm{H}_{2} \mathrm{O}$ at the highest and lowest compliance settings $\left(0.15\right.$ versus $\left.0.01 \mathrm{~L} \cdot \mathrm{cm} \mathrm{H}_{2} \mathrm{O}^{-1}\right)$, respectively. Higher PIP leads to an increase in gas compression in the ventilator circuits [44]. A reduction in delivered tidal volume accounts for up to $20 \%$ [45] of the problem. Hence, the measured tidal volume level of ventilators makes the circuit compliance a critical factor, with consequent estimation errors for alveolar ventilation. Pressure-controlled ventilation is capable of providing a more consistent tidal volume.

\section{Limitations}

This study used the lung simulator model due to medical ethical reasons. A dual adult lung simulator by TTL instrument simulated accurate, normal, and a variety of pathological pulmonary conditions. It is widely used to replace humans to research many invasive treatments. Our study used the TTL to mimic various pulmonary conditions to investigate the effect on ventilator-related parameters during mechanical ventilation with closed suction. It is plausible that some limitations could have influenced the results obtained. CSS uses endotracheal suctioning to remove secretions to prevent obstruction of the tube and lower airways in mechanical ventilation patients. Accumulation of secretion decreases the diameter of endotracheal tubes as well as being a factor in rising airway resistance. The ventilator-related parameters may be underestimated during closed suctioning, where there is a secretion in the airway. In addition, in this experiment, results are only relevant to patients with obstructive or restrictive conditions using closed suction and are unable to be applied to a discussion on the patient coexistence with obstructive and restrictive respiratory systems.

\section{Conclusions}

In this study, most ventilation-related parameter effects during closed suction appear to result from the size of endotracheal tubes paired with suction catheters, ventilation mode, and the patient's pulmonary mechanics. An increase in PIP was produced by reducing the ventilation area during VC-CMV. The decrease in Vexp depends on the size of the suction catheter during PC-CMV. Patients with a progressive decline in their pulmonary mechanics will produce additional effects. However, in patients with severe pulmonary mechanics, these effects will gradually decrease. 
Patients with an obstructive respiratory system should be given smaller dimension catheters in CSS to avert an increase of intrathoracic pressure during VC-CMV, and an intrinsic PEEP should be developed during PC-CMV. Patients with restrictive diseases of the respiratory system will reserve more Vexp and maintain PEEP if the size of the suction catheter is reduced and PC-CMV is selected. The patient's delivered alveolar volume can be overestimated during VC-CMV because the increased compression volume in breathing circuits is neglected at a higher PIP level. When patients with different respiratory system issues experience closed endotracheal suctioning, we believe that selecting the optimal size of the suction catheter will create a more stable and desirable change in ventilator-related parameters.

Author Contributions: Conceptualization, F.J. and G.-M.J.; methodology, F.J.; software, F.J.; validation, S.-H.Y. and J.-C.L.; formal analysis, F.J. and S.-H.Y.; investigation, F.J. and J.-C.L.; resources, F.J; data curation, S.-H.Y. and F.J.; writing — original draft preparation, F.J.; writing-review and editing, J.-C.L. and G.-M.J.; visualization, G.-M.J.; supervision, S.-S.P.C. and G.-M.J.; project administration, S.-S.P.C. and G.-M.J. All authors have read and agreed to the published version of the manuscript.

Funding: This research received no external funding.

Institutional Review Board Statement: Not applicable.

Informed Consent Statement: Not applicable.

Data Availability Statement: The authors confirm that the data supporting the findings of this study are available within the article.

Acknowledgments: We thank the Department of Respiratory Therapy of Fu Jen Catholic University for providing the equipment of the TTL, Hamilton G5 ventilator, and the software of the Hamilton Medical ventilator data logger which allowed us to perform the study.

Conflicts of Interest: The authors declare that there is no conflict of interest regarding the publication of this paper.

\section{References}

1. Taheri, P.; Asgari, N.; Mohammadizadeh, M.; Golchin, M. The effect of open and closed endotracheal tube suctioning system on respiratory parameters of infants undergoing mechanical ventilation. Iran. J. Nurs. Midwifery Res. 2012, 17, $26-29$.

2. Haghighat, S.; Yazdannik, A. The practice of intensive care nurses using the closed suctioning system: An observa-tional study. Iran. J. Nurs. Midwifery. Res. 2015, 20, 619-625. [CrossRef] [PubMed]

3. Iannuzzi, M.; De Robertis, E.; Rispoli, F.; Piazza, O.; Tufano, R. A complication of a closed-tube endotracheal suction catheter. Eur. J. Anaesthesiol. 2009, 26, 974-975. [CrossRef]

4. Maggiore, S.M.; Lellouche, F.; Pigeot, J.; Taille, S.; Deye, N.; Durrmeyer, X.; Richard, J.-C.; Mancebo, J.; Lemaire, F.; Brochard, L. Prevention of Endotracheal Suctioning-induced Alveolar Derecruitment in Acute Lung Injury. Am. J. Respir. Crit. Care Med. 2003, 167, 1215-1224. [CrossRef] [PubMed]

5. Cereda, M.; Villa, M.; Colombo, E.; Greco, G.; Nacoti, M.; Pesenti, A. Closed system endotracheal suctioning maintains lung volume during volume controlled mechanical ventilation. Intensive Care Med. 2001, 27, 648-654. [CrossRef]

6. Dyhr, T.; Bonde, J.; Larsson, A. Lung recruitment manoeuvres are effective in regaining lung volume and oxygenation after open endotracheal suctioning in acute respiratory distress syndrome. Crit. Care 2002, 7, 55-62. [CrossRef]

7. Lindgren, S.; Odenstedt, H.; Olegård, C.; Sondergaard, S.; Lundin, S.; Stenqvist, O. Regional lung derecruitment after endotracheal suction during volume- or pressure-controlled ventilation: A study using electric impedance tomography. Intensiv. Care Med. 2006, 33, 172-180. [CrossRef]

8. Kolobow, T.; Moretti, M.P.; Fumagalli, R.; Mascheroni, D.; Prato, P.; Chen, V.; Joris, M. Severe impairment in lung function induced by high peak airway pressure during mechanical ventilation. An experimental study. Am. Rev. Respir. Dis. 1987, 135, 312-315.

9. Dean, J.; Kolsum, U.; Hitchen, P.; Gupta, V.; Singh, D. Clinical characteristics of copd patients with tidal expiratory flow limitation. Int. J. Chron. Obstruct. Pulmon. Dis. 2017, 12, 1503-1506. [CrossRef] [PubMed]

10. Haake, R.; Schlichtig, R.; Ulstad, D.R.; Henschen, R.P. Barotrauma. Pathophysiology, risk factors, and prevention. Chest 1987, 91, 608-613. [CrossRef]

11. Malhotra, A. Low-Tidal-Volume Ventilation in the Acute Respiratory Distress Syndrome. New Engl. J. Med. 2007, 357, 1113-1120. [CrossRef]

12. Reddy, R.M.; Guntupalli, K.K. Review of ventilatory techniques to optimize mechanical ventilation in acute exac-erbation of chronic obstructive pulmonary disease. Int. J. Chron. Obstruct. Pulmon. Dis. 2007, 2, 441-452. 
13. Chen, L.; Xia, H.-F.; Shang, Y.; Yao, S.-L. Molecular Mechanisms of Ventilator-Induced Lung Injury. Chin. Med. J. 2018, 131, 1225-1231. [CrossRef] [PubMed]

14. Ahmed, S.M.; Athar, M. Mechanical ventilation in patients with chronic obstructive pulmonary disease and bronchial asthma. Ind. J. Anaesth. 2015, 59, 589-598. [CrossRef] [PubMed]

15. Andersen, G.N.; Nilsson, K.; Pourazar, J.; Hackett, T.-L.; Kazzam, E.; Blomberg, A.; Waldenström, A.; Warner, J.; RantapääDahlqvist, S.; Mincheva-Nilsson, L.; et al. Bronchoalveolar matrix metalloproteinase 9 relates to restrictive lung function impairment in systemic sclerosis. Respir. Med. 2007, 101, 2199-2206. [CrossRef] [PubMed]

16. Koulouras, V.; Papathanakos, G.; Papathanasiou, A.; Nakos, G. Efficacy of prone position in acute respiratory distress syndrome patients: A pathophysiology-based review. World, J. Crit. Care Med. 2016, 5, 121-136. [CrossRef] [PubMed]

17. Tonetti, T.; Vasques, F.; Rapetti, F.; Maiolo, G.; Collino, F.; Romitti, F.; Camporota, L.; Cressoni, M.; Cadringher, P.; Quintel, M.; et al Driving pressure and mechanical power: New targets for VILI prevention. Ann. Transl. Med. 2017, 5, 286. [CrossRef] [PubMed]

18. Slutsky, A.S.; Ranieri, V.M. Ventilator-Induced Lung Injury. Neww Engl. J. Med. 2013, 369, 2126-2136. [CrossRef]

19. Lionetti, V.; Recchia, F.A.; Ranieri, V.M. Overview of ventilator-induced lung injury mechanisms. Curr. Opin. Crit. Care 2005, 11, 82-86. [CrossRef]

20. Network, A.R.D.S.; Brower, R.G.; Matthay, M.A.; Morris, A.; Schoenfeld, D.; Thompson, B.T.; Wheeler, A. Ventilation with Lower Tidal Volumes as Compared with Traditional Tidal Volumes for Acute Lung Injury and the Acute Respiratory Distress Syndrome. N. Engl. J. Med. 2000, 342, 1301-1308. [CrossRef]

21. Frengley, R.W.; Closey, D.N.; Sleigh, J.W.; Torrance, J.M. The effect of closed system suction on airway pressures when using the Servo 300 ventilator. Crit. Care Resusc. J. Austr. Acad. Crit. Care Med. 2001, 3, 230-235.

22. Unal, S.; Ergenekon, E.; Kazanci, E.; Aktas, S.; Kulali, F.; Murat, I.; Turkyilmaz, C.; Atalay, Y. Effects of a closed system suction connector on airway resistance in ventilated neonates. Turk. J. Med. Sci. 2017, 47, 923-927. [CrossRef] [PubMed]

23. Harada, N. Closed suctioning system: Critical analysis for its use. Jpn. J. Nurs. Sci. 2010, 7, 19-28. [CrossRef] [PubMed]

24. Rosen, M.; Hillard, E.K. Further considerations on tracheal suction catheters. Br. J. Anaesth. 1963, 35, 125-127. [CrossRef]

25. Magee, P.T. Gas flow between coaxial tubes: Impedance to gas flow in an endotracheal tube increases with a catheter within. Proc. Inst. Mech. Eng. Part. H J. Eng. Med. 2012, 226, 491-494. [CrossRef] [PubMed]

26. Russian, C.J.; Gonzales, J.F.; Henry, N.R. Suction Catheter Size: An Assessment and Comparison of 3 Different Calculation Methods. Respir. Care 2014, 59, 32-38. [CrossRef] [PubMed]

27. Morrow, B. Closed-system suctioning: Why is the debate still open? Ind. J. Med. Sci. 2007, 61, 177-178. [CrossRef]

28. Pryor, L.N.; Baldwin, C.E.; Ward, E.C.; Cornwell, P.L.; O'Connor, S.N.; Cn, M.; Chapman, M.J. Tracheostomy Tube Type and Inner Cannula Selection Impact Pressure and Resistance to Air Flow. Respir. Care 2016, 61, 607-614. [CrossRef]

29. Boussarsar, M.; Thierry, G.; Jaber, S.; Roudot-Thoraval, F.; Lemaire, F.; Brochard, L. Relationship between ventilatory settings and barotrauma in the acute respir-atory distress syndrome. Intensive Care Med. 2002, 28, 406-413. [CrossRef]

30. Tsuno, K.; Prato, P.; Kolobow, T. Acute lung injury from mechanical ventilation at moderately high airway pressures. J. Appl. Physiol. 1990, 69, 956-961. [CrossRef]

31. Natalini, G.; Tuzzo, D.; Rosano, A.; Testa, M.; Grazioli, M.; Pennestrì, V.; Amodeo, G.; Berruto, F.; Fiorillo, M.; Peratoner, A.; et al. Effect of external PEEP in patients under controlled mechanical ventilation with an auto-PEEP of $5 \mathrm{~cm} \mathrm{H}_{2} \mathrm{O}$ or higher. Ann. Intensiv. Care 2016, 6, 53. [CrossRef]

32. Gass, R.; Merola, P.; Monteiro, M.B.; Cardoso, D.M.; Paiva, D.N.; Teixeira, P.J.; Knorst, M.M.; Berton, D.C. Effects of Expiratory Positive Airway Pressure on Exercise Tolerance, Dynamic Hyperinflation, and Dyspnea in COPD. Respir. Care 2017, 62, 1298-1306. [CrossRef] [PubMed]

33. Thille, A.W.; Rodriguez, P.; Cabello, B.; Lellouche, F.; Brochard, L. Patient-ventilator asynchrony during assisted mechanical ventilation. Intensiv. Care Med. 2006, 32, 1515-1522. [CrossRef] [PubMed]

34. Kasim, I.; Gulyas, M.; Almgren, B.; Högman, M. A recruitment breath manoeuvre directly after endotracheal suction improves lung function: An experimental study in pigs. Upsala J. Med. Sci. 2009, 114, 129-135. [CrossRef] [PubMed]

35. Sakuramoto, H.; Jesmin, S.; Shimojo, N.; Kamiyama, J.; Islam, M.; Khatun, T.; Kawano, S.; Mizutani, T. Effects of closed vs. open repeated endotracheal suctioning during mechanical ventilation on the pulmonary and circulatory levels of Endothelin-1 in a lavage induced surfactant depleted Rabbit ARDS model. Life Sci. 2013, 93, e65. [CrossRef]

36. Xu, Z.; Shi, L.; Wang, Y.; Zhang, J.; Huang, L.; Zhang, C.; Liu, S.; Zhao, P.; Liu, H.; Zhu, L.; et al. Pathological findings of COVID-19 associated with acute respiratory distress syndrome. Lancet Respir. Med. 2020, 8, 420-422. [CrossRef]

37. Cha, K.-S.; Park, H.-R. Endotracheal Colonization and Ventilator-associated Pneumonia in Mechanically Ventilated Patients according to Type of Endotracheal Suction System. J. Korean Acad. Nurs. 2011, 41, 175-181. [CrossRef] [PubMed]

38. Cavalcanti, A.B.; Suzumura, E.A.; Laranjeira, L.N.; de Moraes Paisani, D.; Petri Damiani, L.; Penna Guimaraes, P.; Renato Romano, E.; de Moraes Refenga, D.; Taniguchi, L.N.T.; Teixeira, C.; et al. Effect of lung recruitment and titrated positive end-expiratory pressure (peep) vs. low peep on mortality in patients with acute respiratory distress syndrome: A randomized clinical trial. JAMA 2017, 318, 1335-1345.

39. Pogson, D.; Shirley, P.; Connolly, E.; Johnston, S. Closed system endotracheal suctioning maintains lung volume during volume controlled mechanical ventilation. Intensive Care Med. 2002, 28, 222. [CrossRef]

40. Tingay, D.G.; Copnell, B.; Grant, C.A.; Dargaville, P.A.; Dunster, K.R.; Schibler, A. The effect of endotracheal suction on regional tidal ventilation and end-expiratory lung volume. Intensiv. Care Med. 2010, 36, 888-896. [CrossRef] 
41. Corley, A.; Sharpe, N.; Caruana, L.R.; Spooner, A.J.; Fraser, F.F. Lung volume changes during cleaning of closed endotracheal suction cath-eters: A randomized crossover study using electrical impedance tomography. Respir. Care 2014, 59, 497-503. [CrossRef] [PubMed]

42. Corley, A.; Spooner, A.J.; Barnett, A.G.; Caruana, L.R.; Hammond, N.E.; Fraser, J.F. End-expiratory lung volume recovers more slowly after closed endotracheal suctioning than after open suctioning: A randomized crossover study. J. Crit. Care 2012, 27, 742.e1-742.e7. [CrossRef] [PubMed]

43. Glass, C.; Grap, M.; Sessler, C. Endotracheal tube narrowing after closed-system suctioning: Prevalence and risk factors. Am. J. Crit. Care 1999, 8, 93-100. [CrossRef] [PubMed]

44. Keszler, M. Volume-targeted ventilation. Early Hum. Dev. 2006, 82, 811-818. [CrossRef] [PubMed]

45. Bartel, L.P.; Bazik, J.R.; Powner, D.J. Compression volume during mechanical ventilation: Comparison of ventilators and tubing circuits. Crit. Care Med. 1985, 13, 851-854. [CrossRef] [PubMed] 